\title{
Management of Giant Ano-Vulvar Condyloma in a Structure with Limited Resources
}

\author{
Mian Dehi Boston1, Dia Jean Marc ${ }^{2}$, Djanhan Lydie, N'Guessan Koffi'1, Guié Privat ${ }^{2}$, \\ Abauleth Yao Raphael ${ }^{1}$, Kouakou Firmin'1, Boni Serges ${ }^{1}$
}

\begin{abstract}
${ }^{1}$ Department of Gynecology and Obstetrics, University and Hospital Center of Cocody (CHUC), Abidjan, Cote d'Ivoire ${ }^{2}$ Department of Gynecology and Obstetrics, University and Hospital Center of Treichville (CHUT), Abidjan, Cote d'Ivoire ${ }^{3}$ Department of Gynecology and Obstetrics, University and Hospital Center of Bouaké (CHUB), Bouaké, Cote d'Ivoire Email: *jmlaminedia@yahoo.fr
\end{abstract}

How to cite this paper: Boston, M.D., Marc, D.J., Lydie, D., Koffi, N'G., Privat, G., Raphael, A.Y., Firmin, K. and Serges, B. (2017) Management of Giant Ano-Vulvar Condyloma in a Structure with Limited Resources. Open Journal of Obstetrics and Gynecology, 7, 1124-1131.

https://doi.org/10.4236/ojog.2017.711113

Received: August 1, 2017

Accepted: October 17, 2017

Published: October 20, 2017

Copyright $\odot 2017$ by authors and Scientific Research Publishing Inc. This work is licensed under the Creative Commons Attribution International License (CC BY 4.0).

http://creativecommons.org/licenses/by/4.0/

\begin{abstract}
Buschke-Lowenstein Tumor (BLT) or Giant Acuminate Condyloma (GAC) is an uncommon clinical entity rarely published in Côte d'Ivoire and Africa. It is a viral infection with increasing sexual transmission due to the resurgence of HIV infection. This observation is the first case recorded in our service in three decades. The treatment is resolutely surgical, in our context of sub-medicalization, in the absence of other therapeutic means. Most of the time the progression is favorable, but the prognosis can be aggravated by the HIV coinfection. Through this observation, the authors insist on the prevention of all sexually transmitted infections, particularly, with HPV and HIV, by sexual education (abstinence, fidelity, port of condom) and the systematic vaccination before any sexual activity.
\end{abstract}

\section{Keywords}

Giant Ano-Vulvar Condyloma, HIV, HPV

\section{Introduction}

The Giant Acuminate Condyloma (GAC) or Buschke-Lowenstein Tumor (BLT) is a benign and rare clinical entity of viral origin with exclusive sexual transmission [1] [2]. It is a destructive and infiltrating local tumor, with "cauliflower" appearance, induced by a latent infection with the Human Papilloma Virus (HPV), in particular strains 6 and 11 and incidentally phenotypes 16 and 18 [3] [4] [5] [6]. The first observations were made by Buschke in 1896 [7]. Then in 1925, Buschke and Lowenstein, gave a fairly accurate description of its voluminous nature, which they then assimilated to a 
"condyloma acuminate close to the cancerous lesions" developed at the expense of the penis. Indeed, even if the GAC presents the histological characteristics of a totally benign tumor, it is presented in a macroscopic aspect giving it the appearance of an infiltrating malignant lesion. In addition, it has an evolutive potential towards the malignancy which imposes, during the surgery, a resection in healthy zone followed by a histological analysis so as not to disregard an underlying epidermoid carcinoma [8].

In the genesis of this benign tumor proliferation, HIV infection seems to be increasingly predominant [9] [10] [11]. In developing countries, the sexually transmitted infections (STI) are common, constituting a favorable context to the discovery of GAC, but there are few articles, in African literature, about this subject. From a case observed at the department of Gynecology and Obstetrics of the University and Hospital Center of Cocody (Abidjan, Côte d'Ivoire), we propose to study the epidemiological, clinical, histological and evolutionary aspects and to insist on the therapeutic possibilities of this disease in our country with limited resources.

\section{Observation}

Mrs. MDB, 30 years old, single with multiple sexual partners and repeated lower genital infections history, treated with local antiseptics. She consults for a voluminous painless tumefaction of the vulva and the perineum of slow and progressive installation. The onset of the symptomatology would go back to six months by the appearance of intense vulvar itching associated with greenish flows. The use of local antiseptics had no beneficial effect on clinical symptomatology. This was followed by the gradual appearance of scattered vulvar eruptions that invaded the entire vulva. These eruptions will then conflux to give a voluminous bud progressively extensive. After various unsuccessful treatments (shamanic and traditional methods), she consulted us. The examination revealed a conserved general condition, a voluminous budding and vegetating tumor in the form of "cauliflower", about $20 \mathrm{~cm} \times 15 \mathrm{~cm}$, occupying the whole vulvar region, extended to the pubis to the perianal region and to thegluteal furrow (Figure 1). There were no pain, induration, or bleeding on contact and no lymphadenopathy at the inguino-crural ganglionic zones. The exploration of STI revealed a type I HIV infection with impaired immune status (the CD4 count was $200 / \mathrm{mm}^{3}$ ). There were no other detectable STIs (syphilis) and the cervical cytology was normal. We thought of the GAG without excluding a vulva cancer.

A large surgical excision,through healthy zone, by cauterization with the electric bistoury was performed by lack of a $\mathrm{CO}_{2}$ laser. The histological analysis of the surgical specimen confirmed the diagnosis of giant condyloma without signs of malignancy (Figure 2).

Daily local care allowed a more or less slow but complete healing after three weeks. An antiretroviral therapy (ARV) has also been prescribed for life. It included a combination of zidovudine, didanosine, efavirenz. The six-month 


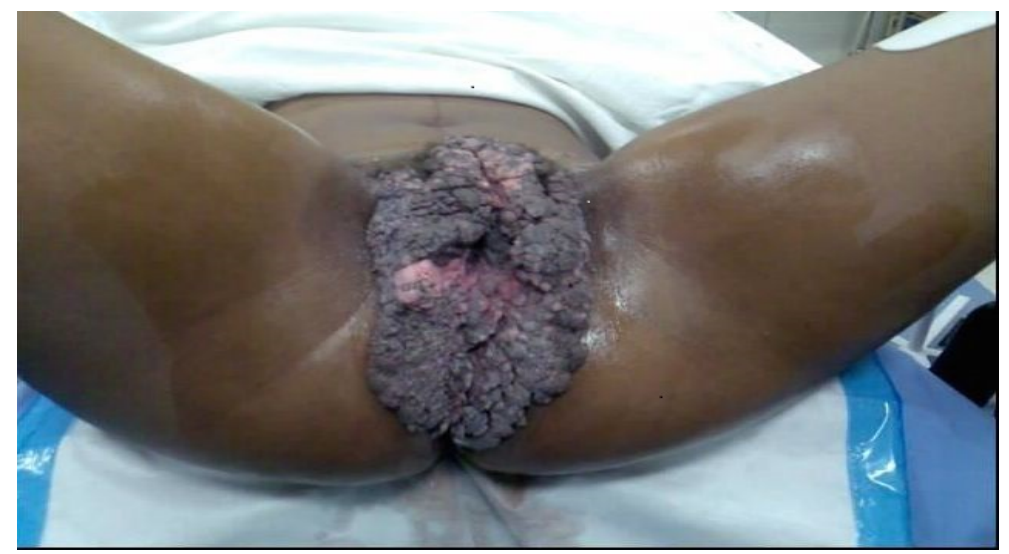

Figure 1. Condyloma inguinal pubo-ano-vulvar giant.

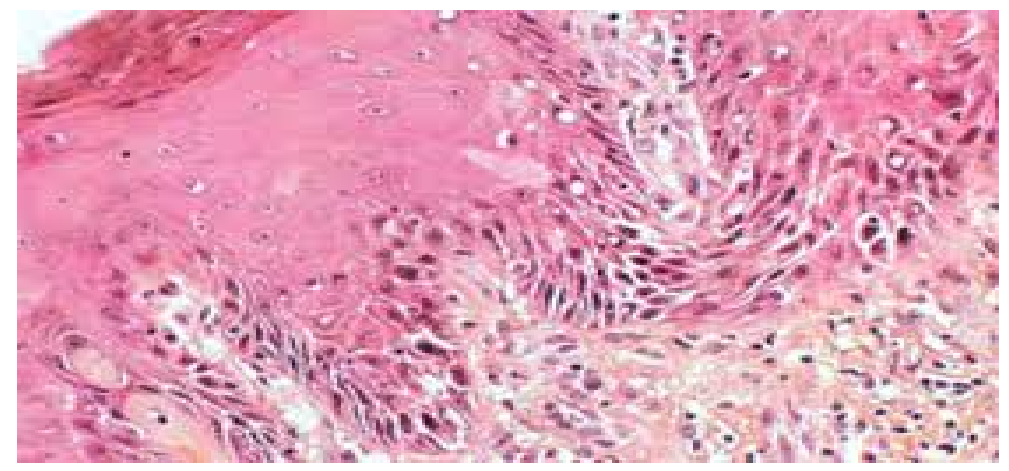

Figure 2. Pathological Aspect $G \times 100$. hematoxylin eosin. Papillomatous hyperplasia with significant extent on the squamous lining koilocytes: papillary appearance, thickened and hyperacanthosic squamous epithelium, cytoplasmic alterations of the squamous cells (koilocytosis, binucleation, nuclear pycnosis).

evaluation found a satisfactory progression, no recurrence and improved immune status $\left(\mathrm{CD} 4\right.$ count $\left.>350 / \mathrm{mm}^{3}\right)$.

\section{Discussion}

The tumor of Buschke-Lowenstein or giant acuminate condyloma (GAC) is a very rare tumor of the ano-vulvar region. Its incidence is estimated at $0.1 \%$ of the general population [4] [5]. It is a sexually transmitted disease characterized by its degenerative potential and invasiveness and recurrence after treatment [1] [4] [5]. This condition affects menmore than women (with a ratio of 3:1), and mainly subjects of an average age of 50 years [12] [13]. In the case reported, the appearence of the GAC in the young patient ( 30 years) would be related to the immune depression due to HIV infection. GAC is a viral disease mainly due to HPV 6 and 11 with low oncogenic potency. However types 16, 18, 31, 33 (known as oncogene) can also cause GAC which can be transformed in cancer [14] [15].

The HPV viral status of our patient could not be specified due to the absence of specialized laboratories. However, the histology of the resection showed the presence of koilocytosis, a highly pathognomonic but non-specific lesion of HPV 
infection. HPV infection, the cause of acuminate condyloma, is common in sexually active women aged 45 years on average [13]. Andthis infection is favored by some well known factors: promiscuity, precarious hygiene, tobacco and immunosuppression. The immunosuppression, due to various causes (HIV infection, diabetes, ethylism or chemotherapy), is responsible for the extensive form of the acuminate condyloma [1] [3] [4]. Besides the absence of circumcision and the resurgence of genital herpes in men, multiplicity of partners, prostitution and homosexuality are also co-factors of the HPV infection [6] [16] [17] [18].

Genital localization is commun and most often asymptomatic [13]. In men, the GAC is localized in more than $80 \%$ of cases in the penis and in less than $20 \%$ of cases in the anorectal region [17] [18]. It may also occur in the urethral level in 5\% of cases in certain series [18] [19]. In women, the location is mostly vulvar $(90 \%)$ as opposed to the anorectal seat which remains less frequent [17] [18]. In our case it was a very large tumor, which occupied the entire inguino-pubo-ano-genital region (Figure 1). GAC usually begins with rounded or filiform pink or normal skin colored lesions. The spontaneous evolution may vary from a few months to several years [17]. The state phase following the invasion is characterized by the appearance of a tumor of large size $(10-15 \mathrm{~cm}$ of major axis) papillomatous, irregular, surface bristling with digitations, budding, Often of a whitish or yellowish color, often showing superficial ulcerations and superficial infectious lesions [17] [20]. In the case reported, the lesion was blackish, necrotic, probably in relation to the lack of local hygiene or the age of the lesions, which in our context of illiteracy can be explained by the delay in the consultation. The presence of bleeding, infiltration of the base or adenopathies should evoke malign degeneration [17] [21].

Due to its rarity, various therapeutic measures have been proposed before a GAC [12]. In countries with limited incomes, the reference treatment is surgical removal by electric scalpel, in the absence of $\mathrm{CO}_{2}$ laser [13]. The surgical specimen must then be analyzed in order to determine the histological nature. In optical microscopy, the GAC appears as a very limited squamous cell carcinoma, characterized by an often pseudo-papillomatous epithelial hyperplasia, the basal membrane of which is still intact. We also notice the presence of a hyperacanthosis, a hyperpillomatosis and koilocytes (pathognomonic markers of the presence of HPV) [17]. The identification of HPV can be done by electron microscopy, immunohistochemical methods and finally by the molecular biology technique either by hybridization or by PCR [22]. All of these diagnostic procedures are not available in our health facilities, making HPV research and typing difficult.

Moreover the search for STIs should be systematic (HIV, chlamydia trachomatis, syphilis) due to some co-infection.

The choice of treatment depends on multiple factors, including localization, surface or deep extension, tumor size, failure of previous therapies [12]. Tyring and Maymon proposed the first-line use of podophyllin solution or gel [23] [24]. Podophyllin is an antimitotic which has the effect of necrosis of the treated 
tissues and thus remains effective on young GACs [24]. The neurotoxic and hematotoxic effects of podophylline limit its use. In front of a small size BLT, some proposed the association cryotherapy-5FU in topical [18] [25] [26]. For some authors, 5FU, intralesional antimitotic, has no effects on TBL [18] [27]. Howeverit can be used as an adjuvant treatment after destruction by electrocoagulation or by the $\mathrm{CO}_{2}$ laser [18] [28] [29]. Electrocoagulation should be reserved for the treatment of GAC in its minor forms because the risk of haemorrhagy is major in advanced forms [18]. $\mathrm{CO}_{2}$ laser vaporization has also been described as a therapeutic method in GAC with $70 \%$ healing rates for a single session [2] [30]. But the Yag laser appears to be more efficient [31].

Interferons may be used intralesionally or parenterally. But their evaluation in current practice is still underestimated in our context because of their high cost. Some found them efficient in the treatment of old and recurrent condylomas [32]. Chemotherapy with systemic bleomycin or methotrexate is a therapeutic alternative, even if it involves an incomplete regression. All these therapeutic means have not been used in the reported observation, either because they are unavailable or because they are expensive. The treatment of choice here has been surgical because it is more effective in the advanced stage of the disease [22] [32]. In the case of infiltrating TBL, the excision must be wider, removing the rectum or the vulva according to some authors [20] [33] [34]. We simply performed a superficial electrocautery whose haemostasis has been laborious but satisfactory. The inguino-crural lymph node dissection is not indicated except in case of degeneration. In some cases, repair may require a cutaneous or muscular flap of proximity. The frequency of recurrences and the risk of epidermoid carcinoma require a prolonged clinical and histological monitoring [35]. In addition to surgery, our patient received antiretroviral treatment for HIV, which she must take for life. The psychological aspect of the care is crucial for Adela due to the negative impact of GAC on the sexual and psychosocial life of the patients [12]. This psychological aspect is often neglected or even rejected in our context because of certain socio-cultural beliefs. Self-vaccination immunotherapy has been a remarkable advance since the commercialization of HPV vaccines. These vaccines are active on the main HPV strains responsible for condylomas (6 and 11). Primary prevention should also be based on information, education of populations in the fight against STIs for behavioral change (through fidelity or abstinence), condom use and vaccination of children before any sexual activity.

\section{Conclusion}

The Buschke-Lowenstein tumor or giant acuminate condyloma is an extremely rare tumor requiring early and wide surgical treatment with rigorous and regular post-surgical monitoring. The association HPV and HIV is very frequent and morbid. Functional and vital prognosis can be initiated in the event of degeneration, hence needing for prevention by systematic anti-HPV vaccination 
before sexual activity and the fight against STIs (screening for HIV infection, sex education).

\section{Conflict of Interest}

The authors declare that they have no conflicts of interest in relation to this article.

\section{References}

[1] Balik, E., Eren, T. and Bugra, D. (2009) A Surgical Approach to Anogenital Buschke-Lowenstein Tumours (Giant Condyloma Acuminata). Acta Chirurgica Belgica, 109, 612-616. https://doi.org/10.1080/00015458.2009.11680497

[2] Frega, A., Stentella, P., Tinari, A., Vecchione, A. and Marchionni, M. (2002) Giant Condyloma Acuminatum or Buschke-Lowenstein Tumor: Review of the Literature and Report of Three Cases Treated by $\mathrm{CO}_{2}$ Laser Surgery. A Long-Term Follow-Up. Anticancer Research, 22, 1201-1204.

[3] Nthumba, P.M., Ngure, P. and Nyoro, P. (2011) Giant Condiloma Acuminatum of the Scrotum in a Man with AIDS: A Case Report. Journal of Medical Case Reports, 5, 272-273. https://doi.org/10.1186/1752-1947-5-272

[4] Yaman, I., Bozdag, A.D., Derici, H., Tansug, T. and Reyhan, E. (2011) Verrucous Carcinoma Arising in a Giant Condyloma Acuminata (Buschke-Lowenstein Tumour): Ten-Year Follow-Up. Annals Academy of Medicine Singapore, 40, 104-105.

[5] Gole, G.N., Shekhar, T., Gole, S.G. and Prabhala, S. (2010) Successful Treatment of Buschke-Lowenstein Tumour by Surgical Excision Alone. Journal of Cutaneous and Aesthetic Surgery, 3, 174-176. https://doi.org/10.4103/0974-2077.74496

[6] Boshart, M. and Zur Hausen, H. (1986) Human Papillomaviruses in Buschke-Lowenstein Tumors: Physical State of the DNA and Identification of a Tandem Duplication in the Noncoding Region of a Human Papillomavirus 6 Subtype. Journal of Virology, 58, 963-966.

[7] Buschke, A. and Lowenstein, L. (1925) Über carcinomahnliche condylomata acuminata des penis. Klin Wochenschr, 36, 1726-1728.

https://doi.org/10.1007/BF01728480

[8] Tripoli, M., Cordova, A., Maggì, F. and Moschella, F. (2012) Giant Condylomata (Buschke-Lowenstein Tumours): Our Case Load in Surgical Treatment and Review of the Current Therapies. European Review for Medical and Pharmacological Sciences, 16, 747-751.

[9] Frazer, I.H. (1998) The Role of the Immune System in Anogenital Human Papillomavirus. Australasian Journal of Dermatology, 39, S5-S7.

[10] Clifford, G.M., Goncalves, M.A. and Franceschi, S. (2006) Human Papillomavirus Types among Women Infected with HIV: A Meta-Analysis. Aids, 20, 2337-2344. https://doi.org/10.1097/01.aids.0000253361.63578.14

[11] Gormley, R.H. and Kovarik, C.L. (2009) Dermatologic Manifestations of HPV in HIV-Infected Individuals. Current HIVI AIDS Reports, 6, 130-138. https://doi.org/10.1007/s11904-009-0018-8

[12] Ciobanu, A.M., Popa, C., Marcu, M. and Ciobanu, C.F. (2014) Psychotic Depression Due to Giant Condyloma Buschke-Löwenstein Tumors. Romanian Journal of Morphology and Embryology, 55, 189-195.

[13] Ondounda, M., Pither, A.S. and Zamba, C. (2012) Giant Anovulvary Condyloma in 
a Gabonese Woman Infected with HIV. Tropical Medicine and Health, 22, 12-13.

[14] Dupin, N. (2004) Genital Warts. Clinics in Dermatology, 22, 481-486.

[15] Braga, J.C.T., Nadal, S.R., Stiepcich, M., De Souza Framil, V.M. and Muller, H. (2012) Buschke-Loewenstein Tumor: Identification of HPV Type 6 and 11 (Condiloma Acuminado Gigante de Buschke-Löwenstein: Identificação dos HPV 6 e 11). Anais Brasileiros de Dermatologia, 87, 131-134. https://doi.org/10.1590/S0365-05962012000100018

[16] Lévy, A. and Lebbe, C. (2006) Buschke-Lowenstein Tumour: Diagnosis and Treatment. Annales D'Urologie (Paris), 40, 175-178.

[17] Reichenbach, I., Koebell, A., Foliguet, B., Hatier, M., Mascotti, J. and Landes, P. (1995) Buschke and Lowenstein Tumor in a Female Case. Journal de Gynécologie Obstétrique et Biologie de la Reproduction, 24, 491-495.

[18] El Mejjad, A., Dakir, M., Tahiri, M., Attar, H., Cherkaoui, A. and Araki, A. (2003) The Giant Acuminate Condyloma-Tumor of Buschke Lowenstein (about 3 Cases). Progress in Urology, 13, 513-517.

[19] The Guillou, M., Geniaux, M., Mugnier, C., Ferriere, J. and Texier, L. (1979) Urethral Localization of Buschke Lowenstein's Disease and an Urethral Tumor. Journal of Urology \& Nephrology, 85, 175-176.

[20] Villote, J., Benhamou, G., Alcabes, G., Vissuzaine, C., Toublanc, M. and Giraud, T. (1989) Buschke-Lowenstein Anorectal Tumor (Giant Condylomatosis) Requiring Amputation of the Rectum. Gastroenterologie Clinique Et Biologique, 13, 105-107.

[21] Kabiri, H., Albouzidi, A., Rachid, K., Lezrek, M., Bousselman, N. and Benomar, S. (1996) Tumeur de Buschke-Loewenstein scrotale dégénérée. Progrès en urologie, 6 , 439-442.

[22] Euvrard, S. and Cardonnet, Y. (1991) Anal Lesions and Human Papillomaviruses: Virological, Epidemiological and Carcinological Aspects. Annales De Dermatologie Et De Venereologie, 118, 497-502.

[23] Tyring, S.K., Arany, I., Stanley, M.A., Tomai, M.A., Miller, R.L., Smith, M.H., et al. (1998) A Randomized, Controlled, Molecular Study of Condylomata Acuminata Clearance during Treatment with Imiquimod. The Journal of Infectious Diseases, 178, 551-555. https://doi.org/10.1086/517472

[24] Maymon, R., Bekerman, Werchow, M., Maymon, B., Segal, R. and Factor, J. (1995) Clinical and Subclinical Condyloma: Rates among Sexual Parteners of Women with Genital Human Papillomavirus Infection. The Journal of Reproductive Medicine, 40, 31-36.

[25] Carson, T.E. (1978) Verrucous Carcinoma of the Penis. Successful Treatment with Cryosurgery and Topical 5-Fluorouracil Therapy. Archives of Dermatology, 114, 1546-1547. https://doi.org/10.1001/archderm.1978.01640220089026

[26] Hughes, P.S. (1979) Cryosurgery of Verrucous Carcinoma of the Penis (Buschke-Lowenstein Tumor). Cutis, 24, 43-45.

[27] Pride, G. (1990) Treatment of Large Lower Genital Tract Condylomaacuminata with Topical 5-Fluorouracil. The Journal of Reproductive Medicine, 35, 384-387.

[28] Bocquet, H. and Bagot, M. (1998) Benign Neoplasms of Viral Origin. Encyclical. Med. Chir. Dermatology, 12-725-A-10, 9 p.

[29] Grosse, G. and Von Kroch, G. (1997) Therapy of Anogenital HPV Induced Lesions. Clinics in Dermatology, 15, 457-470.

[30] Perisic, Z., Lazic, J.P., Terzic, B., Perisic, S. and Rasic, R. (2003) Condylomata Gi- 
gantea in Anal and Perianal Region: Surgical and CO2 Laser Treatment. Archives of Gynecology and Obstetrics, 267, 263-265.

[31] Asch, P. (1997) Infectious Virus Risk and Co2 Laser. Annales De Dermatologie Et De Venereologie, 124, 557-558.

[32] Asvesti, C., Delmas, V., Dauge Geffroy, M., Grossin, M., Boccon-Gibod, L. and Boquet, L. (1991) Multiple Urethral and Bladder-Like Condylomas Revealing HIV Infection. Annales D'Urologie, 25, 146-149.

[33] Bouziani, A. (1994) Verrucous Carcinoma of the Anus (Buschke-Lowenstein Tumor): An Observation with Literature Review. La Semaine Des Hopitaux De Paris, 9-10, 287-291.

[34] Doutre, M., Beylot, C., Bioulac, P. and Baudet, J. (1979) Buschke Lowenstein Tumor: 2 Female Cases. Annales De Dermatologie Et De Venereologie, 106, 1031-1034.

[35] Bergbranti, M., Samuelsson, L., Olofsson, S. and Jonassen, F. (1993) Polymerase Chain Reaction for Mautoring HPV Contamination of Medical Personnel during Treatment of Genital Warts with $\mathrm{CO}_{2}$ Laser and Electrocoagulation. Acta Dermato- Venereologica, 73, 465-466. 